\title{
Ecology of hemiepiphytism in fig species is based on evolutionary correlation of hydraulics and carbon economy
}

\section{Citation}

Hao, Guang-You, Guillermo Goldstein, Lawren Sack, N. Michele Holbrook, Zhi-Hui Liu, Ai-Ying Wang, Rhett D. Harrison, Zhi-Hui Su, and Kun-Fang Cao. 2011. "Ecology of Hemiepiphytism in Fig Species Is Based on Evolutionary Correlation of Hydraulics and Carbon Economy." Ecology 92 (11) (November): 2117-2130. doi:10.1890/11-0269.1.

\section{Published Version}

doi:http://dx.doi.org/10.1890/11-0269.1

\section{Permanent link}

http://nrs.harvard.edu/urn-3:HUL.InstRepos:14350494

\section{Terms of Use}

This article was downloaded from Harvard University's DASH repository, and is made available under the terms and conditions applicable to Other Posted Material, as set forth at http:// nrs.harvard.edu/urn-3:HUL.InstRepos:dash.current.terms-of-use\#LAA

\section{Share Your Story}

The Harvard community has made this article openly available.

Please share how this access benefits you. Submit a story.

\section{Accessibility}




\title{
Ecology of hemiepiphytism in fig species is based on evolutionary correlation of hydraulics and carbon economy
}

\author{
Guang-You Hao, ${ }^{1,2,8}$ Guillermo Goldstein, ${ }^{2,3}$ Lawren Sack, ${ }^{4}$ N. Michele Holbrook, ${ }^{5}$ Zhi-Hui Liu, ${ }^{1,6}$ \\ Ai-Ying Wang, ${ }^{1}$ Rhett D. Harrison,,${ }^{1}$ Zhi-Hui Su, ${ }^{7}$ and Kun-Fang CaO ${ }^{1}$ \\ ${ }^{1}$ Key Laboratory of Tropical Forest Ecology, Xishuangbanna Tropical Botanical Garden, Chinese Academy of Sciences, \\ Menglun, Mengla, Yunnan Province 666303 China \\ ${ }^{2}$ Department of Biology, University of Miami, Coral Gables, Florida 33124 USA \\ ${ }^{3}$ Laboratorio de Ecología Funcional, Departamento de Ciencias Biológicas, Facultad de Ciencias Exactas y Naturales, \\ Universidad de Buenos Aires, Ciudad Universitaria Nuñez, Buenos Aires, Argentina \\ ${ }^{4}$ Department of Ecology and Evolutionary Biology, University of California, 621 Charles E. Young Drive South, \\ Los Angeles, California 90095 USA \\ ${ }^{5}$ Department of Organismic and Evolutionary Biology, Harvard University, Cambridge, Massachusetts 02138 USA \\ ${ }^{6}$ College of Forestry, Guangxi University, Nanning, Guangxi Province 530005 China \\ ${ }^{7}$ JT Biohistory Research Hall, 1-1 Murasaki-cho, Takatsuki, Osaka 5691125 Japan
}

\begin{abstract}
Woody hemiepiphytic species (Hs) are important components of tropical rain forests, and they have been hypothesized to differ from non-hemiepiphytic tree species (NHs) in adaptations relating to water relations and carbon economy; but few studies have been conducted comparing ecophysiological traits between the two growth forms especially in an evolutionary context. Using common-garden plants of the genus Ficus, functional traits related to plant hydraulics and carbon economy were compared for seven NHs and seven Hs in their adult terrestrial "tree-like" growth phase. We used phylogenetically independent contrasts to test the hypothesis that differences in water availability selected for contrasting suites of traits in $\mathrm{Hs}$ and $\mathrm{NHs}$, driving evolutionary correlations among functional traits including hydraulic conductivity and photosynthetic traits. Species of the two growth forms differed in functional traits; Hs had substantially lower xylem hydraulic conductivity and stomatal conductance, and higher instantaneous photosynthetic water use efficiency. Leaf morphological and structural traits also differed strikingly between the two growth forms. The Hs had significantly smaller leaves, higher leaf mass per area (LMA), and smaller xylem vessel lumen diameters. Across all the species, hydraulic conductivity was positively correlated with leaf gas exchange indicating high degrees of hydraulic-photosynthetic coordination. More importantly, these correlations were supported by correlations implemented on phylogenetic independent contrasts, suggesting that most trait correlations arose through repeated convergent evolution rather than as a result of chance events in the deep nodes of the lineage. Variation in xylem hydraulic conductivity was also centrally associated with a suite of other functional traits related to carbon economy and growth, such as LMA, water use efficiency, leaf nutrient concentration, and photosynthetic nutrient use efficiency, indicating important physiological constraints or trade-offs among functional traits. Shifts in this trait cluster apparently related to the adaptation to drought-prone canopy growth during the early life cycle of Hs and clearly affected ecophysiology of the later terrestrial stage of these species. Evolutionary flexibility in hydraulics and associated traits might be one basis for the hyperdiversification of Ficus species in tropical rain forests.
\end{abstract}

Key words: adaptation; comparative method; correlated evolution; Ficus spp.; hydraulic conductivity; leaf mass per area; photosynthesis; phylogenetic independent contrasts; trade-off; tropical rain forest; water use efficiency.

\section{INTRODUCTION}

The plant water transport system shows strong adaptation to environment, particularly in its efficiency and safety. Even closely related species can show striking differences in their hydraulics and water relations, which determine their ability to perform and

Manuscript received 13 February 2011; revised 16 May 2011; accepted 24 May 2011. Corresponding Editor: F. C. Meinzer.

${ }^{8}$ E-mail: guangyou_hao@hks.harvard.edu survive in contrasting environments (Bhaskar et al. 2007, Choat et al. 2007, Hao et al. 2008). Hemiepiphytes with an epiphytic growth stage during part of their lifetime may have evolved unique hydraulic traits related to the drought-prone canopy environment, and comparative studies between closely related hemiepiphytic and non-hemiepiphytic tree species may provide important information to explain the great success of hemiepiphytes in tropical rain forests (Harrison 2005). The aim of this study was to determine the evolutionary 
association of functional traits, especially hydraulic traits, with growth form divergence in hemiepiphytic $(\mathrm{H})$ and non-hemiepiphytic $(\mathrm{NH})$ tree species of Ficus to provide a new model for understanding the hemiepiphytic life-form.

Ficus species are one of the most important components of tropical lowland rain forests globally with additional ecological significance due to their interactions with many plant and animal species (Shanahan et al. 2001, Harrison 2005). There are about 800 Ficus species, including shrubs, climbers, and small-to-large trees of which about 500 species have hemiepiphytic habit (Berg and Corner 2005). Moreover, the hemiepiphytic growth habit has most likely evolved four times independently in the genus (Fig. 1A). Hemiepiphytic figs have limited water availability during the epiphytic canopy growth stage, and may thus have undergone selection for drought-tolerant traits (Holbrook and Putz 1996a, b).

Indeed, given their limited rooting volume and substrate, the epiphytic-phase Hs frequently experience water limitation. Epiphytic-phase individuals of hemiepiphytic Ficus species of tropical seasonal forest are more conservative in their water use, with lower stomatal conductance and cuticular conductance than terrestrially rooted individuals in both wet and dry seasons (Holbrook and Putz 1996a, b). Hemiepiphytic Ficus species undergo major changes in structure and function during the transition from the epiphytic to terrestrial phase (Putz and Holbrook 1986, Holbrook and Putz 1996a,b). However, one study of woody species in neotropical forests showed that terrestrially rooted $\mathrm{Hs}$ had lower leaf-specific xylem hydraulic conductivity than NHs, indicating a constitutive adaptation to lower water supply (Patiño et al. 1995). Differences in hydraulics between growth forms would signal variation in a suite of functionally correlated traits including photosynthetic rate (Brodribb and Field 2000, Santiago et al. 2004a, $b$, Franks 2006, Zhang and Cao 2009). We predicted that compared to NHs, Hs would exhibit traits related to conservative water use and adaptation to drought, such as lower stomatal conductance and higher photosynthetic water use efficiency.

Plant ecophysiological traits interact with one another and the ecological implications of these traits cannot be viewed in isolation. Correlations among functional traits and growth forms provide insights into the mechanisms required for adaptation (Meinzer 2003, Bucci et al. 2004). However, cross-species correlations among plant functional traits do not necessarily imply coevolution, but rather might indicate that after traits shifted coincidentally they were conserved during subsequent diversification (Felsenstein 1985, Ackerly and Reich 1999). On the other hand, divergence in deep nodes can mask subsequent correlated evolutionary changes such that correlations among traits in extant taxa are weakened (Ackerly and Donoghue 1998). This is especially the case in Ficus, where relatively few transitions from NHs to Hs have occurred (Fig. 1A).
Besides solving the statistical problem of nonindependence of species, Felsenstein's method of phylogenetic independent contrasts (PIC) also provides a powerful tool to test for correlated evolutionary change and contributes to the interpretation of evolutionary processes (Felsenstein 1985, Garland et al. 1992, Schwilk and Ackerly 2001). The correlation between independent contrasts is quantitatively equivalent to the correlation between evolutionary changes that have occurred along each branch of the phylogeny (Felsenstein 1985).

In the present study, we examined the correlated evolution of 18 ecophysiological traits related to xylem water transport and leaf physiology among 14 congeneric (Ficus) species by applying PIC analyses with explicit phylogenetic information. The use of closely related species is also advantageous for studying ecophysiological traits that are relatively labile to evolutionary change (Ackerly et al. 2000). We specifically tested for correlated evolution between xylem hydraulic conductivity and gas exchange and among three key functional traits that have been demonstrated crucial in plant functioning, i.e., leaf-specific hydraulic conductivity, leaf mass per area, and water use efficiency (Knight and Ackerly 2001, Zhang and Cao 2009, Wright et al. 2010). This is the first detailed test of hydraulicphotosynthetic coordination in a group of closely related species, and furthermore, it investigated the ecophysiological divergence between hemiepiphytic and non-hemiepiphytic tree species.

\section{Methods}

\section{Study site and plant materials}

This study was conducted in Xishuangbanna Tropical Botanical Garden (XTBG) $\left(21^{\circ} 56^{\prime} \mathrm{N}, 101^{\circ} 15^{\prime} \mathrm{E}, 600 \mathrm{~m}\right.$ altitude), the Chinese Academy of Sciences, Yunnan, Southwest China. The mean annual precipitation is $\sim 1500$ $\mathrm{mm}$ and the mean annual temperature is $22.7^{\circ} \mathrm{C}$. We selected 14 species of Ficus (Moraceae) that occur naturally in tropical rain forests of Xishuangbanna, seven $\mathrm{Hs}$ and seven NHs (Fig. 1B), spanning a wide range of phylogeny and representing as many evolutionary transitions from non-hemiepiphytic to hemiepiphytic growth form as possible (Fig. 1A, B). All plants sampled were mature and growing under similar conditions at XTBG, providing a common environment for the analysis of evolutionary differences (Garland and Adolph 1991). Individuals of the Hs were adults with roots well established in the soil. Ficus tinctoria is a hemi-epiphyte that usually does not form a self-supporting trunk and falls down if the host tree dies; the other six Hs form self-supporting trunks and become large independent trees (see Plate 1), with $F$. altissima typically forming multiple trunks interconnected by aerial roots. The seven NHs are medium- to large-sized trees with single trunks.

\section{Hydraulic conductivity}

Stem hydraulic conductivity $\left(K_{\mathrm{h}}\right)$ was measured on three branches per tree for six to eight individuals per 


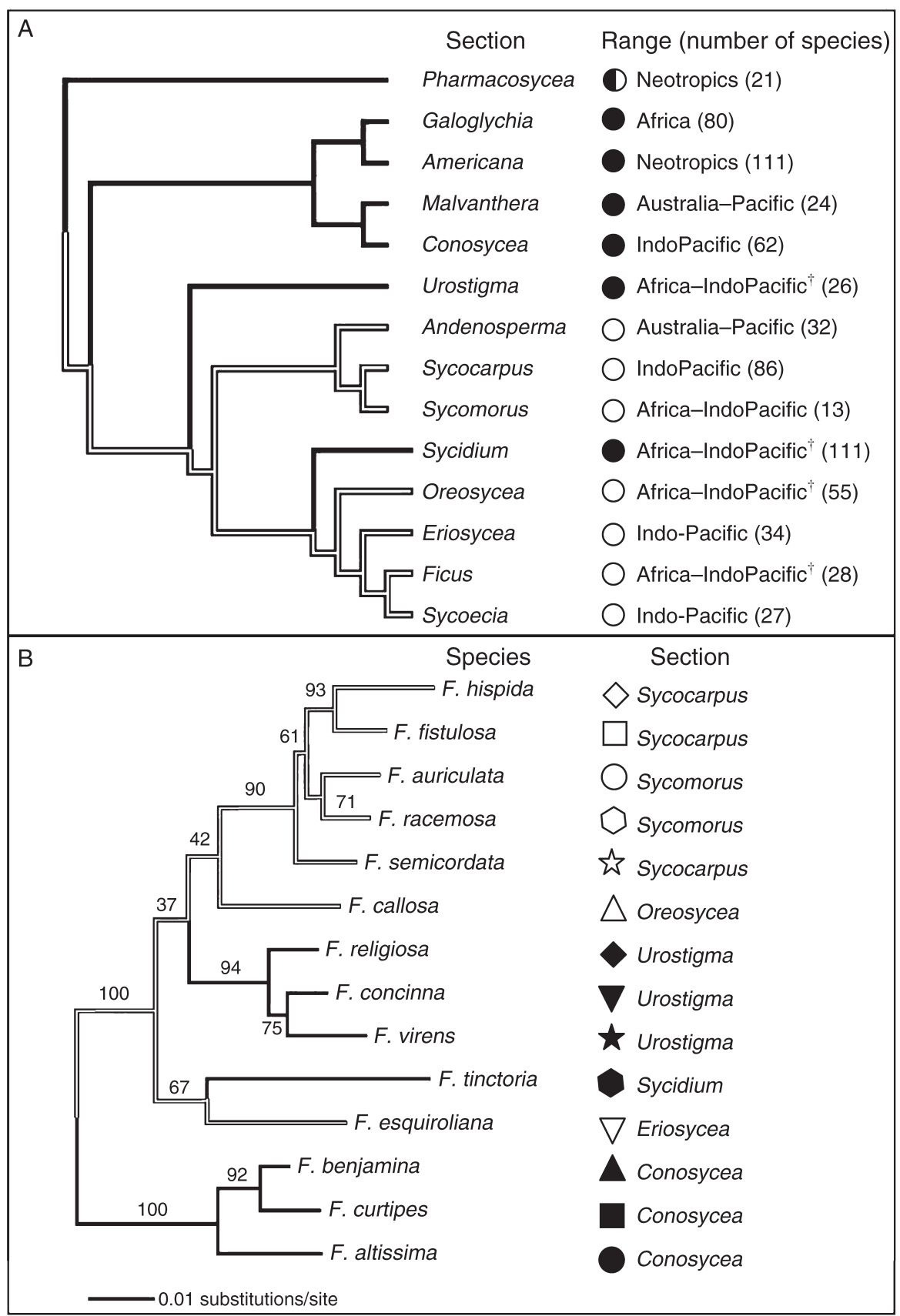

FIG. 1. (A) Phylogeny of the genus Ficus, showing the distribution of growth forms, taxonomic sections, geographic range, and species richness. Solid and open circles indicate hemiepiphytic and non-hemiepiphytic growth forms, respectively. In the section Pharmacosycea both growth forms coexist. Daggers indicate center of diversity. The figure is adapted from Harrison (2005). (B) Bootstrap 50\% majority-rule consensus tree constructed by maximum likelihood (ML) method using the nuclear ITS (internal transcribed spacer) sequences of 14 Ficus species. The bootstrap values are shown at branching points.

species. The three $K_{\mathrm{h}}$ values for each individual were averaged for further analyses. Maximum vessel length was estimated according to Zimmermann and Jeje (1981) and mean values were not significantly different between $\mathrm{Hs}$ and NHs $(64.7$ and $53.4 \mathrm{~cm}$, respectively; $t$ test, $P=0.43)$. In most cases it was impossible to get long branches to avoid a few very long open vessels and thus $50-\mathrm{cm}$ segments were used for all species. Early in the morning, terminal branches $\sim 1 \mathrm{~m}$ long were excised using a tree pruner with a $3-\mathrm{m}$ pole. The cut ends of the branches were recut immediately under water $(\sim 5 \mathrm{~cm}$ removed) and leaves were misted with water to prevent transpiration. With the cut end kept under water and the whole branches wrapped in plastic bags, samples were 
quickly transported to the laboratory and a segment $\sim 50 \mathrm{~cm}$ in length and $0.8-1.2 \mathrm{~cm}$ in diameter was cut off each branch under water; leaves distal to the segment were stored in plastic bags for later use in leaf area determination. All the Ficus species measured produce latex from the bark and pith, and these tissues were removed at both ends $(\sim 1 \mathrm{~cm})$ of the segments without damaging sapwood. Gaps in the center of the stem resulting from the removal of the pith were filled with rubber clay to stop flow of latex from the inner part of pith. After recutting with a sharp razor blade at both ends, the stem segment was connected to an apparatus with degassed and filtered $5 \mathrm{mmol} / \mathrm{L} \mathrm{KCl}$ solution for $K_{\mathrm{h}}$ determination. A hydrostatic pressure driving water flow through the stem segments was generated by a hydraulic head of $50 \mathrm{~cm}$. The downstream end of the segment was connected to a graduated pipette and the time required for the meniscus in the pipette to cross a certain number of consecutive graduation marks was recorded. Hydraulic conductivity $\left(\mathrm{kg} \cdot \mathrm{m} \cdot \mathrm{s}^{-1} \cdot \mathrm{MPa}^{-1}\right)$ was calculated as:

$$
K_{\mathrm{h}}=J_{\mathrm{v}} /(\Delta P / \Delta L)
$$

where $J_{\mathrm{v}}$ is flow rate through the segment $(\mathrm{kg} / \mathrm{s})$ and $\Delta P /$ $\Delta L$ is the pressure gradient across the segment $(\mathrm{MPa} / \mathrm{m})$. Sapwood area $\left(A_{\mathrm{sw}}\right)$ was determined at $1 \mathrm{~cm}$ from both ends by pushing toluidine blue solution through the segment and averaged. The total area of leaves distal to the stem segment $\left(A_{1}\right)$ was measured using a LI-3000 leaf area meter (LI-COR, Lincoln, Nebraska, USA), and the leaf area to sapwood area ratio (LA/SA) was calculated as $A_{1}$ divided by $A_{\text {sw }}$. Sapwood-specific hydraulic conductivity $\left(K_{\mathrm{s}} ; \mathrm{kg} \cdot \mathrm{m}^{-1} \cdot \mathrm{s}^{-1} \cdot \mathrm{MPa}^{-1}\right)$ was calculated as $K_{\mathrm{h}}$ divided by $A_{\mathrm{sw}}$ and leaf-specific hydraulic conductivity $\left(K_{1}, \mathrm{~kg} \cdot \mathrm{m}^{-1} \cdot \mathrm{s}^{-1} \cdot \mathrm{MPa}^{-1}\right)$ as $K_{\mathrm{h}}$ divided by $A_{1}$.

Sapwood samples from the middle of the same branch segments used for hydraulic conductivity measurements were used for determination of wood density ( $\left.\rho_{\text {wood }}\right)$. Sapwood with bark and pith removed was saturated in water overnight. The surface was wiped dry, and the sapwood volume was measured using the water-displacement method, and the sapwood was oven dried at $60^{\circ} \mathrm{C}$ for $72 \mathrm{~h}$ before determining dry mass. Wood density was calculated as dry mass divided by fresh volume.

\section{Sapwood anatomy}

We determined stem xylem vessel diameter for small branches ( $\sim 1 \mathrm{~cm}$ diameter). Cross sections $20-40 \mu \mathrm{m}$ thick were made using a slicing microtome, and xylem vessel lumen diameters (mean values of short and long axes) were determined using an optical microscope at 400× (YS100; Nikon, Ibaraki, Japan). Measurements were made on 30-50 randomly chosen vessels from the middle part of a sapwood cross section for 4-6 branches with each from a different tree.

\section{Leaf form and composition}

Traits relating to gross leaf morphology and composition were determined for 10-20 sun-exposed mature leaves from each of six individuals per species. Total area of leaves sampled from each individual was measured using a LICOR 3000 area meter and divided by leaf number to calculate leaf size (LS). These leaves were oven-dried at $70^{\circ} \mathrm{C}$ for $48 \mathrm{~h}$ before determination of dry mass, and then powdered in a coffee mill for chemical analysis. The leaf mass per area (LMA) was calculated as leaf dry mass divided by area. Total leaf $\mathrm{N}$ concentration was determined with an auto-Kjeldahl unit (K370; BÜCHI Labortechnik AG, Flawil, Switzerland) after digestion with concentrated $\mathrm{H}_{2} \mathrm{SO}_{4}$, and total $\mathrm{P}$ and $\mathrm{K}$ concentrations were analyzed using an inductively coupled plasma atomic-emission spectrometer (IRIS Advantage-ER; Thermo Jarrell Ash, Franklin, Massachusetts, USA) after digestion with concentrated $\mathrm{HNO}_{3}-\mathrm{HClO}_{4}$.

Fresh leaf disks were sampled and saturated overnight in distilled water to determine leaf saturated mass (SM). The saturated water content (SWC) was calculated as $(\mathrm{SM}-\mathrm{DM}) / \mathrm{DM}$, where DM represents dry mass. The fresh volume of leaf disks ( $\mathrm{LV}$ ) was measured using the water displacement method with a balance, and leaf density was calculated as DM/LV.

\section{Leaf gas exchange}

Leaf gas exchange was measured with a portable photosynthetic system (LI-6400; LI-COR, Lincoln, Nebraska, USA). Measurements were made between 08:00 and 11:30 hours during clear days in the 2007 wet season. We measured sun-exposed leaves from the ground or using a ladder. The photosynthetic irradiance was maintained at $1000 \mu \mathrm{mol} \cdot \mathrm{m}^{-2} \cdot \mathrm{s}^{-1}$ at the leaf surface. The leaf cuvette temperature was maintained at $30^{\circ} \mathrm{C}$, chamber $\mathrm{CO}_{2}$ at ambient, and vapor pressure deficit ranged from 0.8 to 1.6 $\mathrm{kPa}$. After gas exchange parameters stabilized, area-based net assimilation rate $\left(A_{\mathrm{a}}\right)$, stomatal conductance $\left(g_{\mathrm{s}}\right)$, and intercellular $\mathrm{CO}_{2}$ concentration $\left(C_{\mathrm{i}}\right)$ were obtained. The intrinsic water-use efficiency $\left(\mathrm{WUE}_{\mathrm{i}}\right)$ was calculated as the ratio of $A_{\mathrm{a}}$ to $g_{\mathrm{s}}$. Three leaves from each of 4-6 individuals of each species were measured, and replicate values from given individuals were averaged for analyses. The massbased net assimilation rate $\left(A_{\mathrm{m}}\right)$, photosynthetic nitrogen use efficiency (PNUE), and photosynthetic phosphorus use efficiency (PPUE) were calculated by dividing $A_{\mathrm{a}}$ by LMA, and by mass-based concentrations of $\mathrm{N}$ and $\mathrm{P}$, respectively.

\section{Construction of the phylogenetic tree}

The phylogenetic relationships among the 14 Ficus species were inferred from nuclear ITS (internal transcribed spacer) sequences (Fig. 1B). Alignments of the ITS sequences were performed using the multiple-alignment program MAFFT (Katoh et al. 2002). Sites including gaps were excluded from the aligned sequence data set and the final length of the sequence data set was $656 \mathrm{nt}$ (nucleotides). The phylogenetic analyses based on the neighbor-joining (NJ) method and the maximum likelihood (ML) method were performed with PAUP 4.0b (Swofford 2001). Kimura's two-parameter distance was 
used for NJ analysis (Kimura 1980). For ML analysis, heuristic searches were implemented using the HKY85 model of the nucleotide substitutions with tree-bisectionreconnection branch-swapping under the default settings. The starting tree was obtained via stepwise addition, with starting branch lengths obtained using the RogersSwofford approximation method. Phylogenetic trees with approximate likelihoods $5 \%$ or farther from the target score were rejected without additional iteration. The trees were evaluated using the bootstrap test based on 1000 replicates.

\section{Statistics and phylogenetic comparative methods}

Differences in functional traits between the two growth forms were tested with one-way analyses of variance using SPSS 16.0 (SPSS, Chicago, Illinois, USA). Principal component analyses (PCA) were performed using the 18 ecophysiological traits. All data were $\log _{10}$-transformed prior to analysis to meet the assumptions of parametric tests. We tested ahistorical correlations (i.e., without considering the phylogeny) among functional traits using Pearson's correlation.

We performed statistical tests in a phylogenetic context using R (version 2.8.1; R Development Core Team 2008). We calculated phylogenetic independent contrasts for each trait after log-transformation, using the phylogenetic tree of the 14 Ficus species (Felsenstein 1985), i.e., the standardized differences in trait values between sister taxa descended from each node of a phylogeny. Three of the 13 contrasts represented nodes between hemiepiphytic or non-hemiepiphytic groups and four within hemiepiphytic groups and six within non-hemiepiphytic groups. We tested the phylogenetic signal using the $K$ statistic and a randomization test implemented via phylogenetically independent contrasts (Blomberg et al. 2003). Phylogenetic ANOVAs were performed to determine the significance of independent evolution of trait differences between $\mathrm{Hs}$ and NHs (Felsenstein 1985, Garland et al. 1993). A principal component analysis of independent contrasts was used to identify the pattern of multivariate correlated evolution among functional traits (Schwilk and Ackerly 2001). To examine the correlated evolution among functional traits, we tested correlations on independent contrasts, fixing lines through the origin (Garland et al. 1992).

\section{RESULTS}

\section{Differences between growth forms}

Hemiepiphytic species (Hs) had lower $K_{\mathrm{s}}$ and $K_{1}$ than their congeneric non-hemiepiphytic species (NHs; Table 1). Consistent with these differences in hydraulic conductivity, Hs had lower stomatal conductance and higher intrinsic water use efficiency than NHs. While light-saturated net $\mathrm{CO}_{2}$ assimilation rates per leaf area did not differ between growth forms, assimilation rates per dry mass basis were significantly lower for Hs (Table 1). Hemiepiphytic species also had lower PNUE and PPUE than NHs. Phylogenetic ANOVAs supported these general patterns arising due to multiple evolution- ary trait shifts; Hs had significantly lower $K_{\mathrm{s}}, g_{\mathrm{s}}, C_{\mathrm{i}}$, and PNUE, and higher $\mathrm{WUE}_{\mathrm{i}}$ than NHs (Table 1). The Hs and NHs showed structural differences in their vascular system consistent with their divergence in hydraulic conductance; Hs had smaller xylem vessel lumen diameters than NHs in small branches (67.5 vs. 76.4 $\mu \mathrm{m}$, respectively; $P<0.05$, one-way ANOVA) and trunk sapwood (181.9 vs. $201.9 \mu \mathrm{m}$, respectively; $P<$ 0.05, one-way ANOVA; G.-Y. Hao, unpublished data). Although sapwood density did not differ significantly between growth forms $(P>0.05)$, Hs tended to have lower hydraulic conductivity at a given wood density $(P$ $<$ 0.05; ANCOVA; Appendix A: Fig. A1).

\section{Principal component analysis}

In the principal component analysis of trait data for the 18 ecophysiological variables, the first two principal components explained $46.2 \%$ and $16.7 \%$ of total variation (Fig. 2A). Plant hydraulic traits (i.e., $K_{\mathrm{s}}$ and $K_{\mathrm{l}}$ ) and gas exchange related traits (i.e., $g_{\mathrm{s}}, C_{\mathrm{i}}, A_{\mathrm{a}}, A_{\mathrm{m}}$, PNUE, and PPUE) clustered together on the positive side of $\mathrm{PC}$ axis 1, whereas traits related to drought adaptation, i.e., LMA, $\rho_{\text {wood, }}$ and $\mathrm{WUE}_{\mathrm{i}}$, were loaded on the negative side of PC axis 1 (Fig. 2A). The first component thus supported the hypothesized strong correlation of xylem water transport and leaf water use and carbon economy. Leaf N, P, and K concentrations were the main contributors to $\mathrm{PC} 2$ and were negatively associated with LMA (Fig. 2A). Hs and NHs were well separated along the first $\mathrm{PC}$ axis and largely overlapping along $\mathrm{PC}$ axis 2 (Fig. 2B).

The principal component analysis of independent contrasts, which indicated correlated trait evolution, showed very similar patterns. The first and second components explained $38.2 \%$ and $14.6 \%$ of the total variation (Fig. 2C). The $\mathrm{PC} 1$ axis indicated the alternative selection of traits relating to higher water transport efficiency to those selected for greater drought tolerance. During evolution, higher hydraulic conductivity was associated with higher stomatal conductance, higher $\mathrm{CO}_{2}$ assimilation rate, and more efficient $\mathrm{N}$ and $\mathrm{P}$ use efficiency, while lower hydraulic conductivity was associated with more conservative water use and higher photosynthetic water use efficiency. The second principal component appears to reflect the negative evolutionary association between LA/SA and efficient xylem water transport and efficiency of $\mathrm{CO}_{2}$ assimilation, showing the effects of resources allocation between leaf and sapwood construction on leaf physiology.

\section{Phylogenetic signal}

The phylogenetic signal in most traits tended to be weak with Blomberg $K$ values $<1$, and no significant signal was found using the randomization test $(P>$ $0.05)$, indicating a high degree of trait lability in most of the ecophysiological traits in this lineage (Appendix B: Table B1). However, a relatively strong phylogenetic 
TABle 1. Comparison of ecophysiological traits between seven hemiepiphytic $(\mathrm{H})$ and seven non-hemiepiphytic (NH) Ficus species (values are mean $\pm \mathrm{SE}$ ).

\begin{tabular}{|c|c|c|c|c|c|c|}
\hline $\begin{array}{l}\text { Functional } \\
\text { trait }\end{array}$ & $\begin{array}{l}\text { Abbreviation } \\
\text { (units) }\end{array}$ & Prediction & $\mathrm{H}$ mean & NH mean & $\begin{array}{c}P \\
\text { (conventional } \\
\text { ANOVA) }\end{array}$ & $\begin{array}{c}P \\
\text { (phylogenetic } \\
\text { ANOVA) }\end{array}$ \\
\hline $\begin{array}{l}\text { Leaf area/sapwood } \\
\text { area ratio }\end{array}$ & $\mathrm{LA} / \mathrm{SA}\left(\mathrm{cm}^{2} / \mathrm{mm}^{2}\right)$ & $\mathrm{H}<\mathrm{NH}$ & $128.7 \pm 18.0$ & $115.2 \pm 18.5$ & 0.291 & 0.400 \\
\hline Sapwood density & $\rho_{\text {wood }}\left(\mathrm{g} / \mathrm{cm}^{3}\right)$ & $\mathrm{H}>\mathrm{NH}$ & $0.50 \pm 0.03$ & $0.45 \pm 0.03$ & 0.100 & 0.241 \\
\hline Leaf size & $\mathrm{LS}\left(\mathrm{cm}^{2}\right)$ & $\mathrm{H}<\mathrm{NH}$ & $84.8 \pm 26.2$ & $296.7 \pm 106.6$ & 0.030 & 0.136 \\
\hline Leaf mass per area & LMA $\left(\mathrm{g} / \mathrm{m}^{2}\right)$ & $\mathrm{H}>\mathrm{NH}$ & $107.0 \pm 12.5$ & $69.1 \pm 6.5$ & 0.007 & 0.066 \\
\hline Leaf density & $\rho_{\text {leaf }}\left(\mathrm{g} / \mathrm{cm}^{3}\right)$ & $\mathrm{H}>\mathrm{NH}$ & $0.34 \pm 0.02$ & $0.29 \pm 0.04$ & 0.083 & 0.228 \\
\hline $\begin{array}{l}\text { Leaf saturated } \\
\text { water content }\end{array}$ & $\mathrm{SWC}(\mathrm{g} / \mathrm{g})$ & $\mathrm{H}<\mathrm{NH}$ & $1.88 \pm 0.14$ & $2.30 \pm 0.15$ & 0.025 & 0.146 \\
\hline $\begin{array}{l}\text { Sapwood-specific } \\
\text { hydraulic } \\
\text { conductivity }\end{array}$ & $K_{\mathrm{s}}\left(\mathrm{kg} \cdot \mathrm{m}^{-1} \cdot \mathrm{s}^{-1} \cdot \mathrm{MPa}^{-1}\right)$ & $\mathrm{H}<\mathrm{NH}$ & $2.00 \pm 0.22$ & $7.06 \pm 1.28$ & 0.001 & 0.015 \\
\hline $\begin{array}{l}\text { Leaf-specific } \\
\text { hydraulic } \\
\text { conductivity }\end{array}$ & $K_{1}\left(\times 10^{-4} \mathrm{~kg} \cdot \mathrm{m}^{-1} \cdot \mathrm{s}^{-1} \cdot \mathrm{MPa}^{-1}\right)$ & $\mathrm{H}<\mathrm{NH}$ & $2.28 \pm 0.45$ & $9.55 \pm 2.71$ & 0.007 & 0.077 \\
\hline $\begin{array}{l}\text { Light-saturated net } \\
\mathrm{CO}_{2} \text { assimi- } \\
\text { lation rate on } \\
\text { leaf area basis }\end{array}$ & $A_{\mathrm{a}}\left(\mu \mathrm{mol} \cdot \mathrm{m}^{-2} \cdot \mathrm{s}^{-1}\right)$ & $\mathrm{H}<\mathrm{NH}$ & $13.0 \pm 0.8$ & $13.7 \pm 0.8$ & 0.274 & 0.370 \\
\hline $\begin{array}{l}\text { Light-saturated } \\
\text { net } \mathrm{CO}_{2} \text { assimi- } \\
\text { lation rate on } \\
\text { leaf mass basis }\end{array}$ & $A_{\mathrm{m}}\left(\mu \mathrm{mol} \cdot \mathrm{g}^{-1} \cdot \mathrm{s}^{-1}\right)$ & $\mathrm{H}<\mathrm{NH}$ & $0.126 \pm 0.016$ & $0.210 \pm 0.028$ & 0.008 & 0.066 \\
\hline $\begin{array}{l}\text { Maximum sto- } \\
\text { matal conduc- } \\
\text { tance }\end{array}$ & $g_{\mathrm{s}}\left(\mathrm{mol} \cdot \mathrm{m}^{-2} \cdot \mathrm{s}^{-1}\right)$ & $\mathrm{H}<\mathrm{NH}$ & $0.301 \pm 0.028$ & $0.408 \pm 0.021$ & 0.003 & 0.046 \\
\hline $\begin{array}{l}\text { Intercellular } \mathrm{CO}_{2} \\
\text { concentration }\end{array}$ & $C_{\mathrm{i}}(\mu \mathrm{mol} / \mathrm{mol})$ & $\mathrm{H}<\mathrm{NH}$ & $290.1 \pm 3.5$ & $305.2 \pm 2.2$ & 0.001 & 0.024 \\
\hline $\begin{array}{l}\text { Intrinsic water-use } \\
\text { efficiency }\end{array}$ & $\mathrm{WUE}_{\mathrm{i}}(\mu \mathrm{mol} / \mathrm{mol})$ & $\mathrm{H}>\mathrm{NH}$ & $44.6 \pm 2.2$ & $34.3 \pm 1.2$ & 0.001 & 0.012 \\
\hline $\begin{array}{l}\text { Leaf nitrogen } \\
\text { content }\end{array}$ & N (\%) & $\mathrm{H}>\mathrm{NH}$ & $2.11 \pm 0.18$ & $1.69 \pm 0.12$ & 0.033 & 0.146 \\
\hline $\begin{array}{l}\text { Leaf phosphorus } \\
\text { content }\end{array}$ & $\mathrm{P}(\%)$ & $\mathrm{H}>\mathrm{NH}$ & $0.15 \pm 0.021$ & $0.15 \pm 0.01$ & 0.454 & 0.482 \\
\hline $\begin{array}{l}\text { Leaf potassium } \\
\text { content }\end{array}$ & K (\%) & $\mathrm{H}>\mathrm{NH}$ & $1.70 \pm 0.23$ & $1.14 \pm 0.13$ & 0.020 & 0.116 \\
\hline $\begin{array}{l}\text { Photosynthetic } \mathrm{N} \\
\text { use efficiency }\end{array}$ & $\begin{array}{l}\text { PNUE } \\
\quad\left(\mu \mathrm{mol} \mathrm{CO}{ }_{2} \cdot \mathrm{s}^{-1} \cdot \mathrm{mol}^{-1} \mathrm{~N}\right)\end{array}$ & $\mathrm{H}<\mathrm{NH}$ & $83.0 \pm 5.9$ & $181.6 \pm 31.1$ & 0.003 & 0.047 \\
\hline $\begin{array}{c}\text { Photosynthetic P } \\
\text { use efficiency }\end{array}$ & $\begin{array}{l}\text { PPUE } \\
\quad(\mu \mathrm{mol} \mathrm{CO} \\
\left.\mathrm{CO}_{2} \cdot \mathrm{s}^{-1} \cdot \mathrm{mol}^{-1} \mathrm{P}\right)\end{array}$ & $\mathrm{H}<\mathrm{NH}$ & $2.71 \pm 0.26$ & $4.35 \pm 0.60$ & 0.010 & 0.089 \\
\hline
\end{tabular}

Notes: Means of the two growth forms were compared using conventional one-way ANOVAs and phylogenetic ANOVAs. We specified the predictions in comparison between growth forms to allow one-tailed significance testing. $P$ values $<0.05$ are shown in bold.

signal was found in $K_{\mathrm{s}}, K_{1}, \mathrm{WUE}_{\mathrm{i}}$, and PNUE, indicating phylogenetic conservatism.

\section{Ahistorical and phylogenetically independent contrasts correlations}

The trait differences between $\mathrm{H}$ and NHs and among species within growth forms resulted in relatively large ranges of trait values, with many correlations among traits, including those consistent with the hypothesis of hydraulic-photosynthetic coordination (Fig. 3A-C). These trait correlations were supported using phylogenetic independent contrasts, indicating the correlated evolution of ecophysiological traits (Fig. 3D-F). The three key functional traits were strongly intercorrelated when analyzed using ahistorical correlations; LMA and WUE $_{\mathrm{i}}$ were both negatively correlated with $K_{1}$, and WUE $_{i}$ was positively correlated with LMA (Fig. 4A-C). When phylogenetic independent contrasts were used, correlation between LMA and $K_{1}$ became insignificant (Fig. 4D), while the other two correlations remained significant (Fig. 4E, F).

Strong evolutionary correlations were found between the three key functional traits (i.e., $K_{1}, \mathrm{LMA}_{\text {, and }} \mathrm{WUE}_{\mathrm{i}}$ ) and other traits (Fig. 5B-D). Leaf-specific hydraulic conductivity correlated strongly with SWC, PNUE, and $g_{\text {s }}$ in evolution, reflecting its impact on leaf water status and photosynthesis. Wood density, leaf area to sapwood area ratio, and water use efficiency showed the strongest negative correlations with $K_{1}$ (Fig. 5B). LMA showed strong evolutionary correlation with SWC, PPUE, $C_{\mathrm{i}}$, PNUE, and $A_{\mathrm{m}}$ (Fig. 5C), reflecting the coordination between leaf structure and function, including water status and photosynthetic gas exchange. Leaf intrinsic water use efficiency showed strong negative correlations with $K_{1}$, PNUE, $g_{\mathrm{s}}$, and $C_{\mathrm{i}}$ (Fig. 5D). 

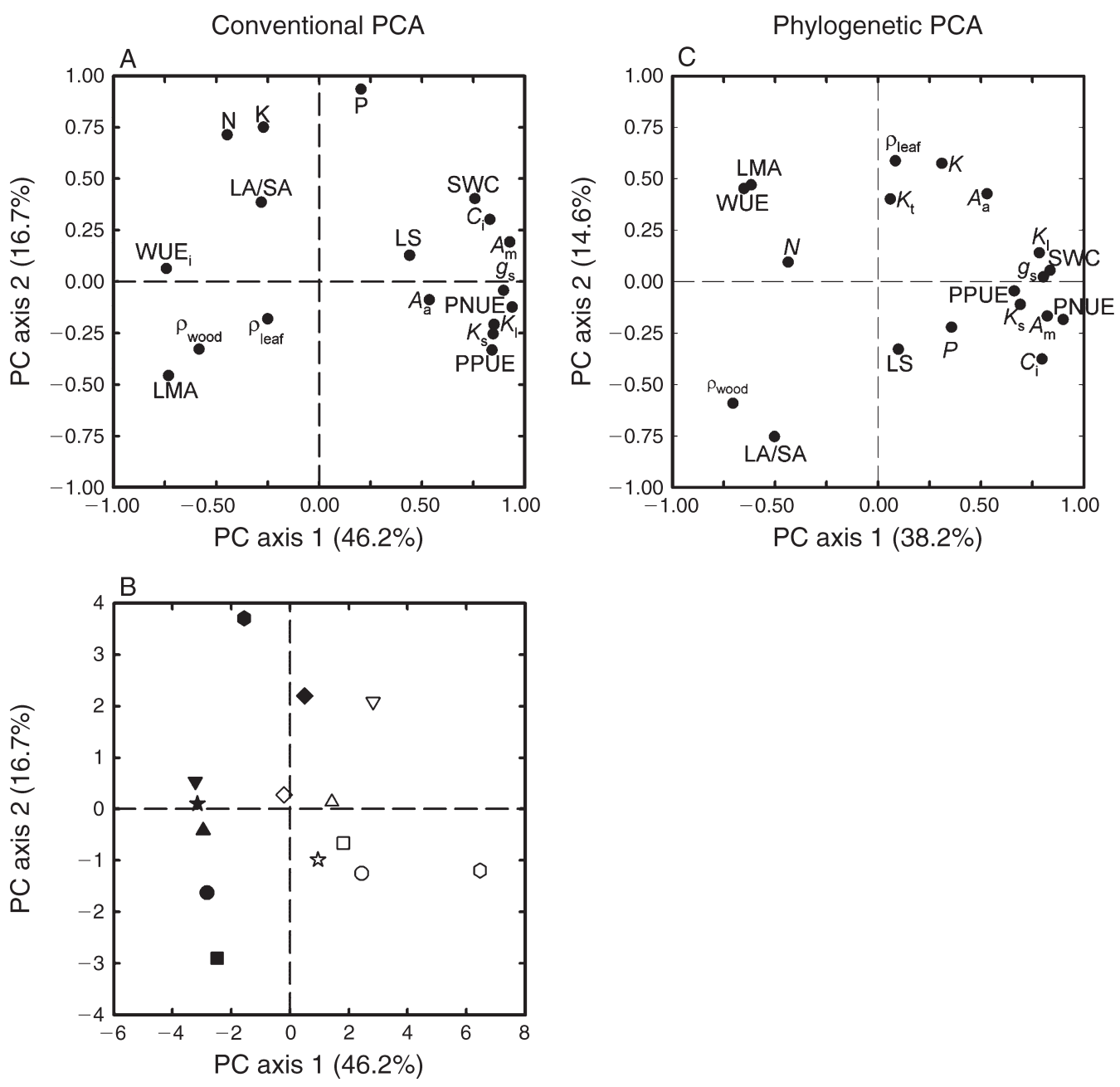

FIG. 2. Arrangement of 18 traits along the first two principal component axes constructed based on (A) species trait values and (B) independent contrasts for the 14 Ficus species. Values in parentheses in the axis labels report the percentage of variation explained. See Table 1 for identification of the traits. Loadings of species along PC axes 1 and 2 are shown in panel (C).

When ahistorical and PIC correlations were compared for all relationships, the evolutionary correlations were similar to ahistorical correlations (Fig. 5A). In most cases the magnitude of the correlation coefficients decreased slightly when analyzed using independent contrasts (points below the diagonal in quadrant 1 and points above the diagonal in quadrant 3 of Fig. 5A); in relatively fewer cases, the strength of correlations increased when independent contrasts were used (points above the diagonal in quadrant 1 and points below the diagonal in quadrant 3 ). In very few cases, the direction of the correlation switched between the ahistorical and evolutionary analyses (points in quadrants 2 and 3), but these correlations were all statistically insignificant.

\section{Discussion}

We found substantial differences between hemiepiphytic and non-hemiepiphytic Ficus species grown in a common garden, in important traits relating to ecological performance, including xylem hydraulic conductiv- ity, leaf water use, and carbon economy. The hemiepiphytic species had xylem with significantly smaller vessel lumen diameters and lower hydraulic conductivity than non-hemiepiphytic species based on both ahistoric and phylogenetic analyses, despite the relatively large variation within each growth form. Leaf gas exchange and carbon economy traits were highly correlated with hydraulic conductivity, and these traits in turn were negatively associated with drought tolerance traits. Phylogenetic analyses indicated that these correlations arose from repeated correlated evolution rather than by chance resulting from a single or few divergent events in the deep nodes of this lineage (common ancestry effect). These findings can be parsimoniously explained by the hypothesis that $\mathrm{Hs}$ are adapted to drought conditions selected for their epiphytic early growth stage in the canopy, whereas NHs are adapted for greater competition given higher water supply in their terrestrial early growth stage. 

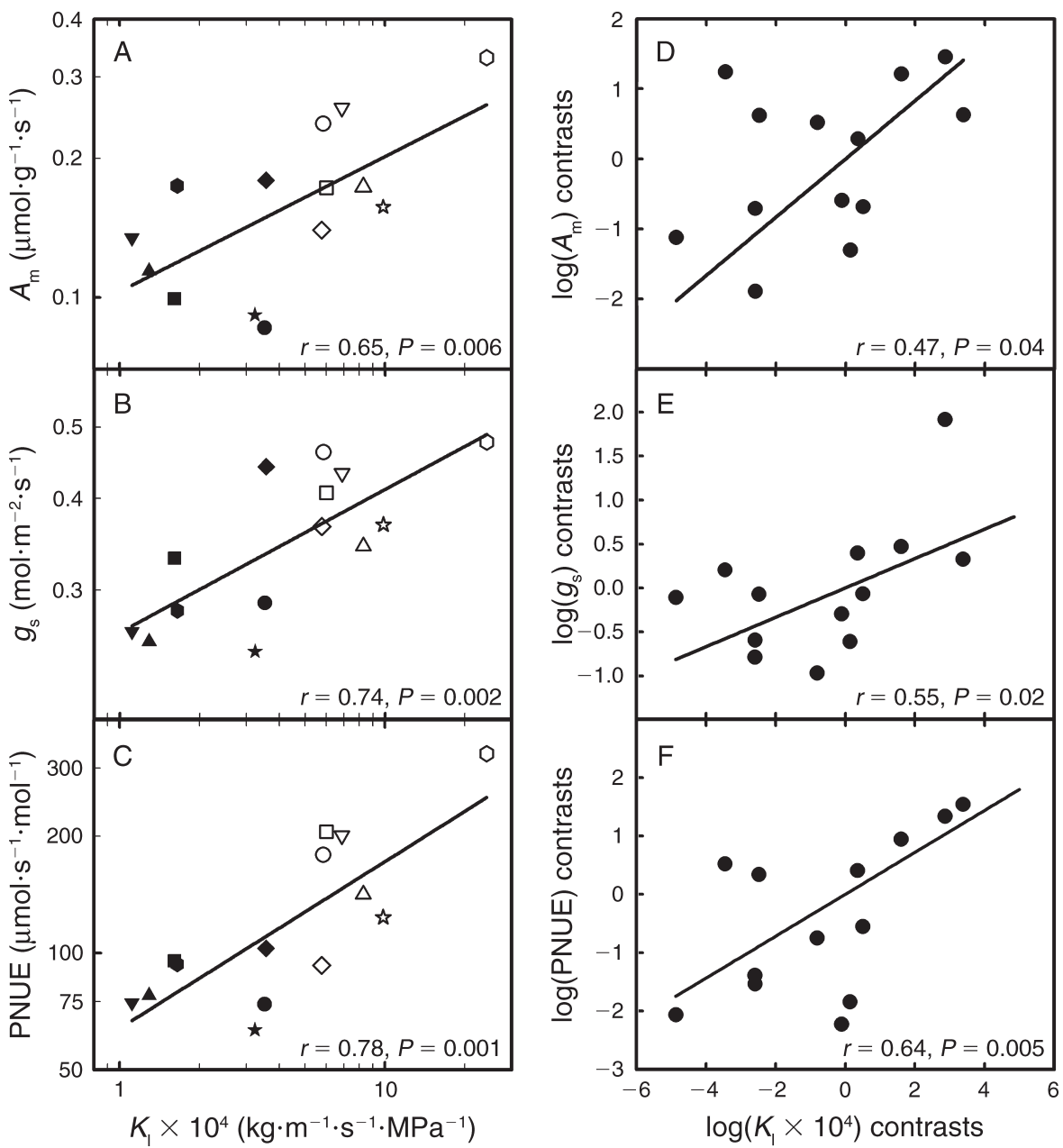

FIG. 3. Correlations of species traits and independent contrasts between leaf gas exchange traits and leaf-specific hydraulic conductivity $\left(K_{\mathrm{l}}\right)$. (A, D) between leaf mass based photosynthetic $\mathrm{CO}_{2}$ assimilation rate $\left(A_{\mathrm{m}}\right)$ and $K_{\mathrm{l}}$; (B, E) between stomatal conductance $\left(g_{\mathrm{s}}\right)$ and $K_{1} ;(\mathrm{C}, \mathrm{F})$ between photosynthetic nitrogen use efficiency (PNUE) and $K_{1}$. Note that in panels (A), (B), and (C) the data have been plotted on logarithmic scales, and the straight lines describe the logarithmic equations fitted to species mean values. Hemiepiphytic and non-hemiepiphytic species are distinguished by solid and open symbols; each species has a different symbol as defined in Fig. 1B.

\section{Divergence between the two growth forms in hydraulic architecture}

The major divergences between Hs and NHs may reflect a trade-off between xylem water transport efficiency and drought tolerance (Martinez-Vilalta et al. 2002). Xylem hydraulic conductivity is influenced by the xylem properties such as the density and diameter of xylem conduits (Tyree et al. 1994), and thus closely related to $\rho_{\text {wood. }}$. Wood density is usually negatively correlated with xylem hydraulic conductivity, sap velocity, and stomatal conductance (Roderick and Berry 2001, Margaret and Whitehead 2003, Bucci et al. 2004). Across these Ficus species, the negative correlation between $\rho_{\text {wood }}$ and $K_{\mathrm{s}}$ was consistent with the general trend in previous studies across species sets, and here extended to diverse closely related species within a lineage. The finding that at a given $\rho_{\text {wood }}$ Hs had lower hydraulic conductivity (Appendix A: Fig. A1) was likely related to their smaller vessel lumen diameters. Smaller vessel lumen diameter would not itself result in higher $\rho_{\text {wood, }}$, as in both Hs and NHs the sapwood vessels accounted for a small portion of the wood matrix relative to fiber cells. However, because vessel hydraulic conductivity is proportional to the fourth power of its diameter according to the Hagen-Poiseuille law (Tyree and Ewers 1991), larger vessels in NHs would result in significantly higher $K_{\mathrm{s}}$. The same pattern of smaller xylem vessel lumen diameters for $\mathrm{Hs}$ was found in petioles as in stems, indicating coordination of function in different parts of the plant water transport pathway. Due to the positive correlation between vessel diameter and maximum inter-vessel pit size, narrower vessels would likely increase the safety of xylems to air-seeding between embolized and water-filled conduits, and thus smaller vessels are often found in more drought-adapted 

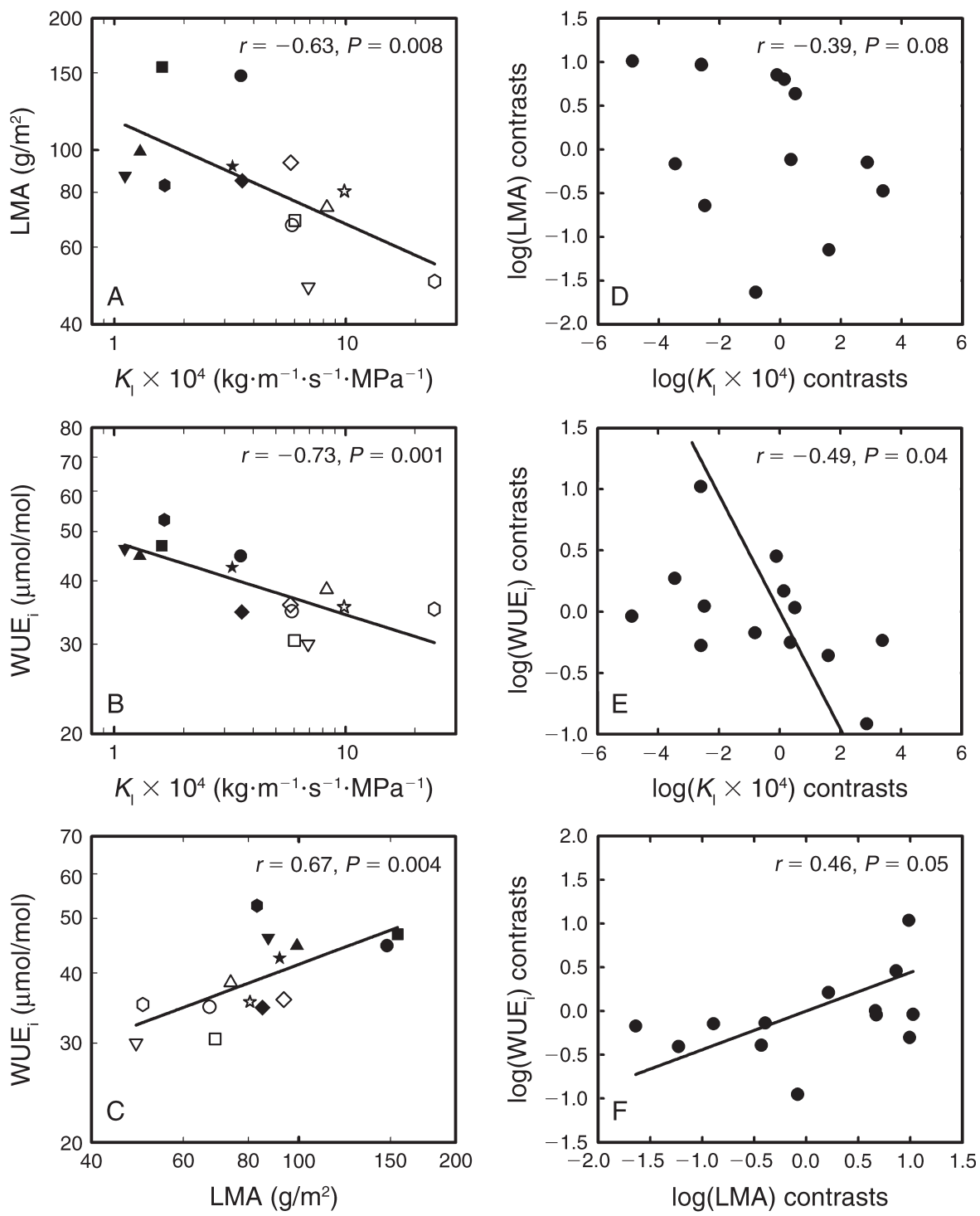

FIG. 4. Correlations of species traits and independent contrasts (A, D) between leaf-specific hydraulic conductivity $\left(K_{1}\right)$ and leaf mass per area (LMA); (B, E) between $K_{1}$ and intrinsic water-use efficiency $\left(\mathrm{WUE}_{\mathrm{i}}\right)$; and $(\mathrm{C}, \mathrm{F})$ between LMA and WUE . Note that in panels (A), (B), and (C) the data have been plotted on logarithmic scales. Symbols are as defined in Fig. 1.

wood (Jarbeau et al. 1995, Martinez-Vilalta et al. 2002), consistent with their appearing in Hs.

The divergences between $\mathrm{Hs}$ and $\mathrm{NHs}$ in hydraulic architecture suggested contrary adaptation in water relations, such that $\mathrm{Hs}$ have lower hydraulic conductivity and lower $\mathrm{CO}_{2}$ assimilation rates when expressed on per unit leaf biomass or nutrient $(\mathrm{N}$ and $\mathrm{P})$ content basis, but greater water use efficiency and drought tolerance. Indeed, several studies of distantly related species within and across communities have shown that species growing in relatively wet environments tend to have greater vulnerability to drought-induced cavitation, and these species tend to have high rates of gas exchange when water is available, which are at least partially explained by their high water transport efficiency (Salleo et al. 2000, Santiago et al. 2004b, but see Brodribb and Hill 1999). It has been argued that a compromise between the ability to cope with drought and to grow rapidly under favorable water conditions can explain the displacement of drought-tolerant species from mesic and humid habitats (Orians and Solbrig 1977). However, Hs with lower hydraulic conductivity have not been outcompeted or displaced by $\mathrm{NHs}$ in humid tropical forests. Indeed, Hs tend to be more successful than NHs in terms of species richness and total biomass throughout humid tropical forests of the world (Harrison 2005). Ficus species tend to be highly light-demanding (Zotz et al. 1995), and the success of Hs may be largely attributable to their growth habit that permits them to colonize the canopy of dense rain 
A) All pairwise

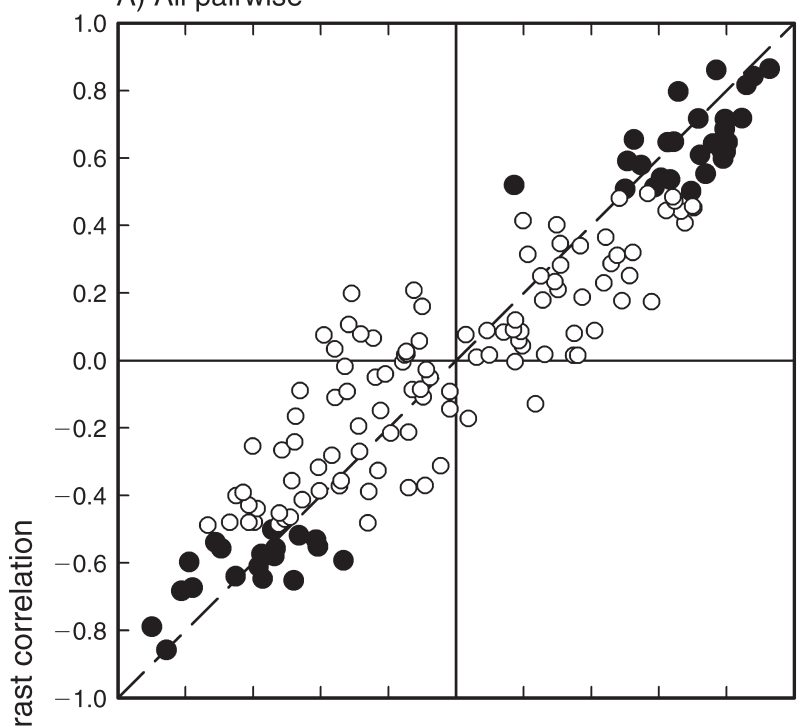

B) Correlations with $K$

\begin{tabular}{l}
$\frac{1}{0}$ \\
$\frac{10}{2}$ \\
$\frac{0}{0}$ \\
$\frac{0}{10}$ \\
\hline
\end{tabular}

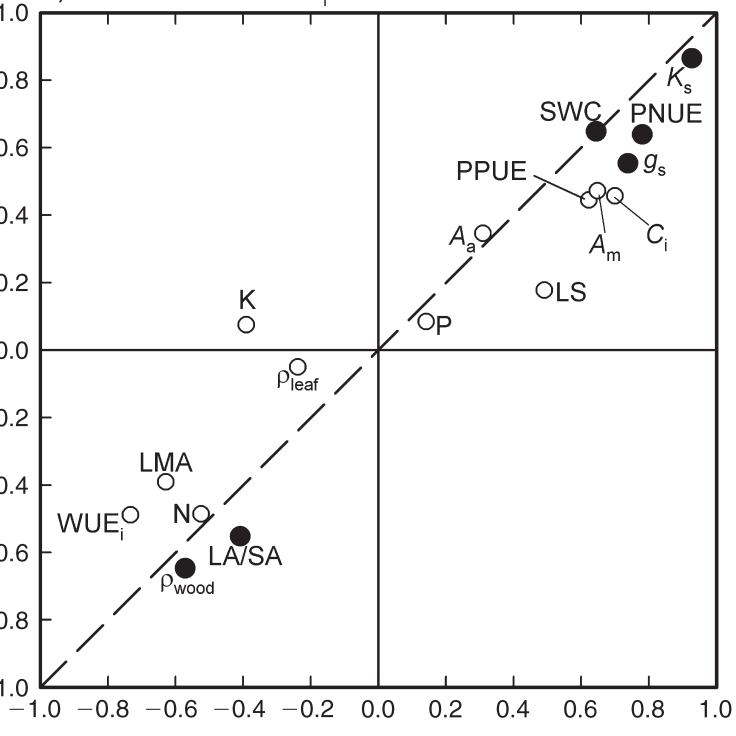

C) Correlations with LMA

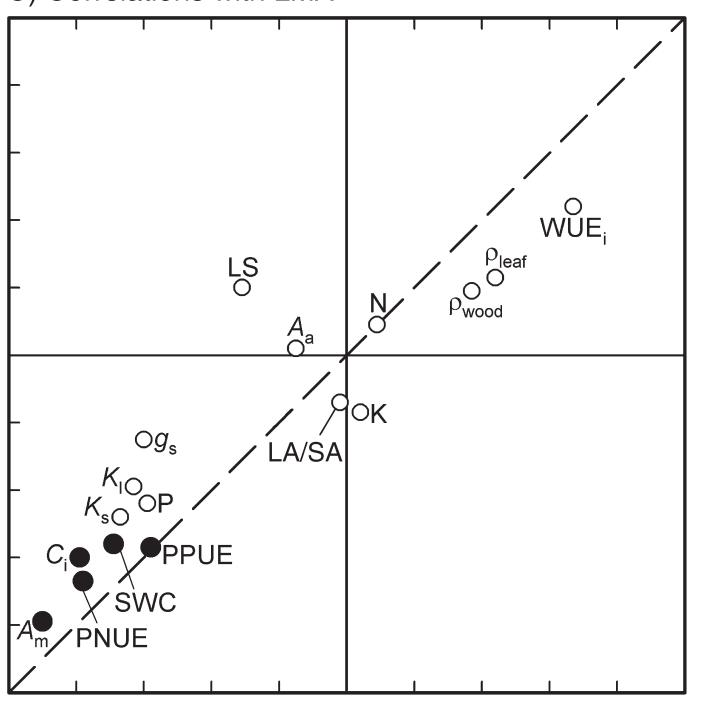

D) Correlations with WUE $_{\mathrm{i}}$

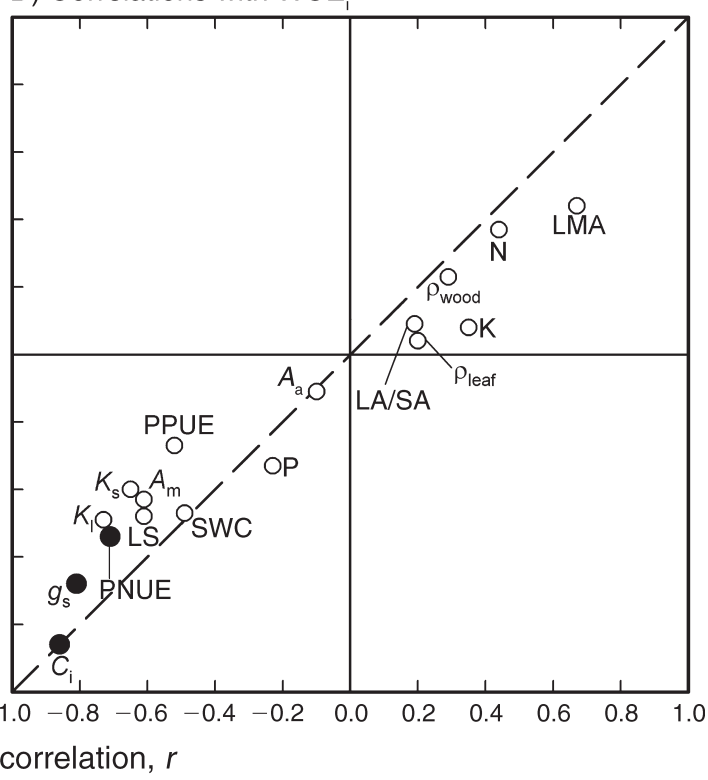

FIG. 5. Scatterplot of cross-species Pearson's correlations ( $r$ ) vs. independent contrast correlations (A) between all possible pairwise traits; (B) between leaf-specific hydraulic conductivity $\left(K_{1}\right)$ and other functional traits; (C) between leaf mass per area (LMA) and other functional traits; and (D) between intrinsic water use efficiency ( $W_{U E}$ ) and other functional traits. Traits with independent contrast correlation coefficients greater than 0.5 or less than -0.5 are identified by solid circles. The dashed line shows $y=x$. Abbreviations for traits are as defined in Table 1 .

forests, which is a widespread microhabitat with high light availability (Harrison et al. 2003). In contrast, most NHs are pioneers dependent on canopy gaps for regeneration and directly compete with a large number of other rain forest tree species (Harrison and Shanahan 2005). Moreover, the hemiepiphytic growth form and its associated functional traits endow these fig species with a high degree of ecological flexibility, enabling them to colonize a wide range of harsh habitats, such as nutrient impoverished peat swamps, rocky cliffs, and littoral environments (Corner 1940).

\section{Hydraulic-photosynthetic coordination and trade-offs among functional traits}

The positive correlation between $K_{1}$ and leaf gas exchange in Ficus was consistent with previous studies that presented coordination between hydraulics and photosynthesis across distantly related species (Brodribb and Field 2000, Melcher et al. 2001, Brodribb et al. 2002, Santiago et al. 2004a, $b$, Franks 2006). The hydraulicphotosynthetic coordination is here extended to closely related Ficus species, and variation in these interlinked 

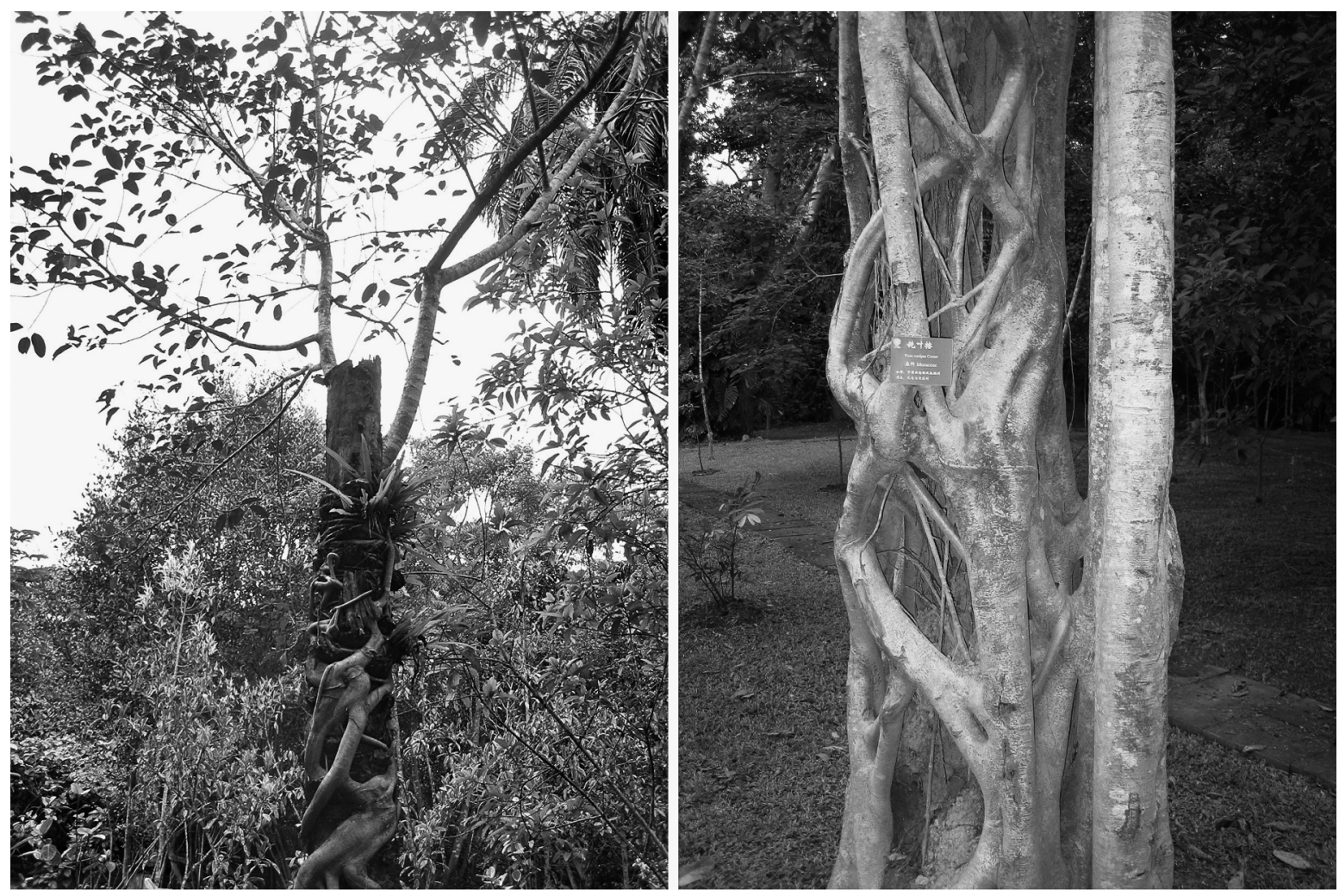

Plate 1. (Left) Ficus curtipes of early growth stage in Xishuangbanna Tropical Botanical Garden (China), with its host tree strangled. (Right) F. curtipes of independent growth stage following the decomposition of the strangled host tree. Photo credits: G. Hao.

traits represents adaptation to the $\mathrm{H}$ vs. $\mathrm{NH}$ life-form. This coordination was well-supported by the principal component analyses. Characteristics related to hydraulic conductivity (i.e., $K_{\mathrm{s}}$ and $K_{1}$ ) and traits related to leaf gas exchange and carbon economy (i.e., $g_{\mathrm{s}}, A_{\mathrm{a}}, A_{\mathrm{m}}$, PNUE, and PPUE) clustered together on the positive side of the PC axis 1 , while WUE $_{\mathrm{i}}, \rho_{\text {wood, }}$, and LMA loaded negatively on $\mathrm{PC}$ axis 1 (Fig. 2A). The positive correlations between $K_{1}$ and leaf gas exchange parameters (i.e., $A_{\mathrm{m}}$ and $g_{\mathrm{s}}$ ) suggested the importance of stem xylem water transport efficiency in enabling rapid water transport to transpiring leaves and consequently higher leaf water potentials and higher $g_{\mathrm{s}}$ (Meinzer et al. 1995, Sperry 2000, Meinzer 2003, Zhang and Cao 2009). The higher $g_{\mathrm{s}}$ in turn results in higher intercellular $\mathrm{CO}_{2}$ concentration and higher photosynthetic rates (Farquhar et al. 1980, Katul et al. 2003). This finding also suggested that hydraulics mediate important ecophysiological trade-offs among the two life-forms in this lineage. The negative correlation between $K_{1}$ and $\mathrm{WUE}_{\mathrm{i}}$ (Fig. 4B) suggested that species with lower hydraulic conductivity tend to use water more efficiently. However, the more conservative water use was associated with lower $\mathrm{CO}_{2}$ assimilation rates, resulting in a trade-off between WUE $_{\mathrm{i}}$ and PNUE (Field et al. 1983, Santiago et al. 2004a, Zhang and Cao 2009).
The correlation between LMA and other functional traits suggested that variation in leaf form plays an important role in adaptation to their environments. LMA is often associated with leaf life span, leaf nitrogen concentration, leaf dark respiration, photosynthetic capacity, and plays important role in shade tolerance (Evans and Poorter 2001). However, variation in LMA among Ficus tree species appears to be mainly related to adaptation to water supply rather than to irradiance, because both $\mathrm{Hs}$ and NHs are high light demanding during both juvenile and adult stages (Zotz et al. 1995; G.-Y. Hao, unpublished data). Higher LMA has been found to be associated with drier environments and an important predictor of habitat preferences among plants (Wright et al. 2004, Hoffmann et al. 2005). Leaves with higher LMA have a larger water storage capacitance and contribute to the maintenance of a more stable leaf water status and hydraulic function under drought (Bucci et al. 2004, Hao et al. 2008, 2010). Higher LMA in Hs may have evolved as an adaptation to lower hydraulic conductivity and water availability, but at the same time strongly affected plant carbon economy due to its intrinsic association with longer leaf life span, lower $\mathrm{N}$ concentration, lower mass based photosynthetic capacity, and other leaf functional traits (Wright et al. 2004). 
These correlations suggest that LMA is the nexus of a suite of functional convergences representing physiological constraints, trade-offs, or correlated responses to environments (Knight and Ackerly 2001).

\section{Phylogenetic signal and correlated evolution of functional traits}

The overall low levels of phylogenetic signal suggested that ecophysiological traits are labile to evolutionary change in Ficus. In studies of other lineages, traits related to plant water relations have shown a wide range of phylogenetic lability, but hydraulics traits have tended to be conservative (Cavender-Bares et al. 2004, Preston et al. 2006). Indeed, $K_{\mathrm{s}}$ and $K_{1}$ were among the few traits in this study with a relatively high degree of "phylogenetic inertia," consistent with the finding that traits related to stem hydraulic architecture were strongly influenced by the phylogenetic history (Hao et al. 2008, Willson et al. 2008). The controlling effect of hydraulic conductivity over photosynthetic capacity has been well studied across diverse species sets (Brodribb and Field 2000, Melcher et al. 2001, Brodribb et al. 2002, Santiago et al. 2004a, $b$, Franks 2006, Zhang and Cao 2009). However, research incorporating explicit phylogeny of the species has been rare, and our analysis of independent contrasts clearly indicated significant evolutionary correlations between hydraulics and photosynthesis (Fig. 3). Further, LMA showed evolutionary correlation with water relations and leaf gas exchange (Fig. 5D), highlighting the role of LMA in linking leaf water balance with carbon assimilation.

Across the traits studied in Hs and NHs, evolutionary correlations were overall consistent with ahistorical correlations (Fig. 5A), indicating that most trait correlations reflected coordinated evolution. In general, large discrepancies between ahistorical and independent contrast correlations tend only to arise among traits highly conserved during evolution (Ackerly and Donoghue 1998). Our study reinforced the general finding that ecophysiological traits are labile during evolution, i.e., showing a high degree of convergent evolution rather than phylogenetic conservatism (Ackerly and Reich 1999, Maherali et al. 2004).

Despite the overall similarity between ahistorical and independent contrasts correlations, in most trait pairs the strength of correlations decreased slightly when using independent contrasts (Fig. 5A). A large divergence among lineages, coupled with reduced divergence within lineages can cause ahistorical correlations to diminish substantially when analyzed using phylogenetic independent methods (Willson et al. 2008). On the other hand, traits with a higher degree of homoplasy usually show less discrepancy between ahistorical and PIC correlations. For most of the measured traits, differences between $\mathrm{H}$ and $\mathrm{NH}$ species were large whereas differences within groups were relatively small, which may be the main reason why most correlations became weaker using PIC analyses. However, in a few cases correlations become stronger when analyzed using independent contrasts, such as the negative correlations between $K_{1}$ and LA/SA (Fig. 5B), which indicated that divergences in deep nodes can mask subsequent correlated evolutionary changes and cause weak correlations in extant taxa (Ackerly and Donoghue 1998, Schwilk and Ackerly 2001). These results further demonstrated the importance of incorporating phylogeny into the analysis of trait correlations.

\section{Conclusions}

These findings support a new model for the evolution and ecology of hemiepiphytism, based on drought tolerance, at the expense of rapid hydraulic transport and gas exchange under well watered conditions as found for non-hemiepiphytic species. Ficus species of the two growth forms showed contrasting clusters of ecophysiological traits, providing an evolutionary model for this specialization, just as this genus has been a model for evolution of plant-insect interactions (Herre et al. 2008). Notably, the differences between Hs and NHs were found to have an evolutionary basis, with trait differences, correlations, and clusters arising from multiple independent events during evolution, and thus largely maintaining significance when analyzed taking phylogeny into account. The adaptation of Hs persists even in the adult terrestrially rooted stage; even if plants at this stage have reliable soil water sources, and undergo dramatic ontogenetic changes in structure and physiology during the transition from epiphyte to rooted phase (Holbrook and Putz 1996a,b), some genetically based traits adapted to the drought-prone epiphytic habitat persist to a large degree into the terrestrial phase. Across growth forms, Ficus species showed strong ahistorical and evolutionary correlations between hydraulic and gas-exchange traits, extending those found across diverse species in previous studies. Many other traits were correlated in evolution with leaf-specific hydraulic conductivity and LMA, reinforcing their central roles in divergence of growth forms, and functional convergence in species of given lineages.

\section{ACKNOWLEDGMENTS}

J.-L. Zhang, M. Helmus, and J. Behm assisted in data analyses, and the L. Sternberg Lab and the Biogeochemistry Laboratory at XTBG assisted in leaf chemical analyses. This study was supported by grants from a major 973 Project, Chinese Ministry of Science and Technology (2006CB403207) and the National Science Foundation, USA (DEB0542912). G.-Y. Hao is currently supported by a Giorgio Ruffolo Post-doctoral Fellowship in Sustainability Science at Harvard University.

\section{Literature Cited}

Ackerly, D. D., and M. J. Donoghue. 1998. Leaf size, sapling allometry, and Corner's rules: a phylogenetic study of correlated evolution in maples (Acer). American Naturalist 152:767-791.

Ackerly, D. D., S. A. Dudley, S. E. Sultan, J. Schmitt, J. S. Coleman, C. R. Linder, D. R. Sandquist, M. A. Geber, A. S. 
Evans, T. E. Dawson, and M. J. Lechowicz. 2000. The evolution of plant ecophysiological traits: recent advances and future directions. BioScience 50:979-995.

Ackerly, D. D., and P. B. Reich. 1999. Convergence and correlations among leaf size and function in seed plants: a comparative test using independent contrasts. American Journal of Botany 86:1272-1281.

Berg, C. C. and E. J. H. Corner. 2005. Moraceae - Ficus. Pages 1-730 in H. P. Nooteboom, editor. Flora Malesiana series I-seed plants, Volume 17/Part 2. National Herbarium of The Netherlands, Leiden, The Netherlands.

Bhaskar, R., A. Valiente-Banuet, and D. D. Ackerly. 2007. Evolution of hydraulic traits in closely related species pairs from mediterranean and nonmediterranean environments of North America. New Phytologist 176:718-726.

Blomberg, S. P., T. Garland Jr., and A. R. Ives. 2003. Testing for phylogenetic signal in comparative data: behavioral traits are more labile. Evolution 57:717-745.

Brodribb, T. J., and T. S. Field. 2000. Stem hydraulic supply is linked to leaf photosynthetic capacity: evidence from New Caledonian and Tasmanian rainforests. Plant, Cell and Environment 23:1381-1388.

Brodribb, T. J., and R. S. Hill. 1999. The importance of xylem constraints in the distribution of conifer species. New Phytologist 143:365-372.

Brodribb, T. J., N. M. Holbrook, and M. V. Gutiérrez. 2002. Hydraulic and photosynthetic co-ordination in seasonally dry tropical forest trees. Plant, Cell and Environment 25:1435-1444.

Bucci, S. J., G. Goldstein, F. C. Meinzer, F. G. Scholz, A. C. Franco, and M. Bustamante. 2004. Functional convergence in hydraulic architecture and water relations of tropical savanna trees: from leaf to whole plant. Tree Physiology 24:891-899.

Cavender-Bares, J., K. Kitajima, and F. A. Bazzaz. 2004. Multiple trait associations in relation to habitat differentiation among 17 Floridian oak species. Ecological Monographs 74:635-662.

Choat, B., L. Sack, and N. M. Holbrook. 2007. Diversity of hydraulic traits in nine Cordia species growing in tropical forests with contrasting precipitation. New Phytologist 175:686-698.

Corner, E. J. H. 1940. Strangling fig trees. Pages 664-665 in Wayside trees of Malaya. First edition. Government Printer, Singapore.

Evans, J. R., and H. Poorter. 2001. Photosynthetic acclimation of plants to growth irradiance: the relative importance of specific leaf area and nitrogen partitioning in maximizing carbon gain. Plant, Cell and Environment 24:755-767.

Farquhar, G. D., S. von Caemmerer, and J. A. Berry. 1980. A biochemical model of photosynthetic $\mathrm{CO}_{2}$ assimilation in leaves of $C_{3}$ species. Planta 149:78-90.

Felsenstein, J. 1985. Phylogenies and the comparative method. American Naturalist 125:1-15.

Field, C., J. Merino, and H. A. Mooney. 1983. Compromises between water-use efficiency and nitrogen-use efficiency in five species of California evergreens. Oecologia 60:384-389.

Franks, P. J. 2006. Higher rates of leaf gas exchange are associated with higher leaf hydrodynamic pressure gradients. Plant, Cell and Environment 29:584-592.

Garland, T., Jr., and S. C. Adolph. 1991. Physiological differentiation of vertebrate populations. Annual Review of Ecology and Systematics 22:193-228.

Garland, T., Jr., A. L. Dickerman, C. M. Janis, and J. A. Jones. 1993. Phylogenetic analysis of covariance by computer simulation. Systematic Biology 42:265-292.

Garland, T., Jr., P. H. Harvey, and A. R. Ives. 1992. Procedures for the analysis of comparative data using phylogenetically independent contrasts. Systematic Biology 41:18-32.

Hao, G.-Y., W. A. Hoffmann, F. G. Scholz, S. J. Bucci, F. C. Meinzer, A. C. Franco, K.-F. Cao, and G. Goldstein. 2008.
Stem and leaf hydraulics of congeneric tree species from adjacent tropical savanna and forest ecosystems. Oecologia 155:405-415.

Hao, G.-Y., L. Sack, A.-Y. Wang, K.-F. Cao, and G. Goldstein. 2010. Differentiation of leaf water flux and drought tolerance traits in hemiepiphytic and non-hemiepiphytic Ficus tree species. Functional Ecology 24:731-740.

Harrison, R. D. 2005. Figs and the diversity of tropical rainforests. BioScience 55:1053-1064.

Harrison, R. D., A. A. Hamid, T. Kenta, J. Lafrankie, H.-S. Lee, H. Nagamasu, T. Nakashizuka, and P. Palmiotto. 2003. The diversity of hemi-epiphytic figs (Ficus, Moraceae) in a Bornean lowland rain forest. Biological Journal of the Linnean Society 78:439-455.

Harrison, R. D., and M. Shanahan. 2005. Seventy-seven ways to be a fig: an overview of a diverse assemblage of figs in Borneo. Pages 111-127 in D. W. Roubik, S. Sakai, and A. A. Hamid Karim, editors. Pollination ecology and the rain forest. Springer, New York, New York, USA.

Herre, E. A., K. C. Jandér, and C. A. Machado. 2008. Evolutionary ecology of figs and their associates: recent progress and outstanding puzzles. Annual Review of Ecology, Evolution, and Systematics 39:439-458.

Hoffmann, W. A., A. C. Franco, M. Z. Moreira, and M. Haridasan. 2005. Specific leaf area explains differences in leaf traits between congeneric savanna and forest trees. Functional Ecology 19:932-940.

Holbrook, N. M., and F. E. Putz. 1996a. Water relations of epiphytic and terrestrially-rooted strangler figs in a Venezuelan palm savanna. Oecologia 106:424-431.

Holbrook, N. M., and F. E. Putz. 1996b. From epiphyte to tree: differences in leaf structure and leaf water relations associated with the transition in growth form in eight species of hemiepiphytes. Plant, Cell and Environment 19:631-642.

Jarbeau, J., F. Ewers, and S. Davis. 1995. The mechanism of water stress induced xylem dysfunction in two species of chaparral shrubs. Plant, Cell and Environment 18:189-196.

Katoh, K., K. Misawa, K. Kuma, and T. Miyata. 2002. MAFFT: a novel method for rapid multiple sequence alignment based on fast Fourier transform. Nucleic Acids Research 30:3059-3066.

Katul, G., R. Leuning, and R. Oren. 2003. Relationship between plant hydraulic and biochemical properties derived from a steady state coupled water and carbon transport model. Plant, Cell and Environment 26:339-350.

Kimura, M. 1980. A simple method for estimating evolutionary rate of base substitutions through comparative studies of nucleotide sequences. Journal of Molecular Evolution 16:111-120.

Knight, C. A., and D. D. Ackerly. 2001. Correlated evolution of chloroplast heat shock protein expression in closely related plant species. American Journal of Botany 88:411-418.

Maherali, H., W. T. Pockman, and R. B. Jackson. 2004. Adaptive variation in the vulnerability of woody plants to xylem cavitation. Ecology 85:2184-2199.

Margaret, M. B., and D. Whitehead. 2003. A demonstration of the theoretical prediction that sap velocity is related to wood density in the conifer Dacrydium cupressinum. New Phytologist 158:477-488.

Martinez-Vilalta, J., E. Prat, I. Oliveras, and P. Josep. 2002. Xylem hydraulic properties of roots and stems of nine Mediterranean woody species. Oecologia 133:19-29.

Meinzer, F. C. 2003. Functional convergence in plant responses to the environment. Oecologia 134:1-11.

Meinzer, F. C., G. Goldstein, P. Jackson, N. M. Holbrook, M. V. Gutiérrez, and J. Cavelier. 1995. Environmental and physiological regulation of transpiration in tropical forest gap species: the influence of boundary layer and hydraulic conductance properties. Oecologia 101:514-522.

Melcher, P. J., G. Goldstein, F. C. Meinzer, D. E. Yount, T. J. Jones, N. M. Holbrook, and C. X. Huang. 2001. Water 
relations of coastal and estuarine Rhizophora mangle: xylem pressure potential and dynamics of embolism formation and repair. Oecologia 126:182-192.

Orians, G. and O. Solbrig. 1977. A cost-income model of leaves and roots with special reference to arid and semiarid areas. American Naturalist 111:677-690.

Patiño, S., M. T. Tyree, and E. A. Herre. 1995. Comparison of hydraulic architecture of woody plants of differing phylogeny and growth form with special reference to free-standing and hemi-epiphytic Ficus species from Panama. New Phytologist 129:125-134.

Preston, K. A., W. K. Cornwell, and J. L. DeNoyer. 2006. Wood density and vessel traits as distinct correlates of ecological strategy in 51 California coast range angiosperms. New Phytologist 170:807-818.

Putz, F. E., and N. M. Holbrook. 1986. Notes on the natural history of hemiepiphytes. Selbyana 9:61-69.

R Development Core Team. 2008. R: a language and environment for statistical computing. R Foundation for Statistical Computing, Vienna, Austria. 〈http://www. R-project.org $\rangle$

Roderick, M. L., and S. L. Berry. 2001. Linking wood density with tree growth and environment: a theoretical analysis based on the motion of water. New Phytologist 149:473-485.

Salleo, S., A. Nardini, F. Pitt, and M. A. L. Gullo. 2000. Xylem cavitation and hydraulic control of stomatal conductance in laurel (Laurus nobilis L.). Plant, Cell and Environment 23:7179.

Santiago, L. S., G. Goldstein, F. C. Meinzer, J. B. Fisher, K. Machado, D. Woodruff, and T. Jones. 2004a. Leaf photosynthetic traits scale with hydraulic conductivity and wood density in Panamanian forest canopy trees. Oecologia 140:543-550.

Santiago, L. S., K. Kitajima, S. J. Wright, and S. S. Mulkey. $2004 b$. Coordinated changes in photosynthesis, water relations and leaf nutritional traits of canopy trees along a precipitation gradient in lowland tropical forest. Oecologia 139:495-502.

Schwilk, D. W., and D. D. Ackerly. 2001. Flammability and serotiny as strategies: correlated evolution in pines. Oikos 94:326-336.

Shanahan, M., S. So, S. G. Compton, and R. Corlett. 2001. Fig-eating by vertebrate frugivores: a global review. Biological Reviews 76:529-572.

Sperry, J. S. 2000. Hydraulic constraints on plant gas exchange. Agricultural and Forest Meteorology 104:13-23.

Swofford, D. L. 2001. PAUP*. Phylogenetic analysis using parsimony (* and other methods), version 4.0 beta version. Sinauer Associates, Sunderland, Massachusetts, USA.

Tyree, M. T., S. D. Davis, and H. Cochard. 1994. Biophysical perspectives of xylem evolution: Is there a tradeoff of hydraulic efficiency for vulnerability to dysfunction? IAWA Journal 15:335-360.

Tyree, M. T., and F. W. Ewers. 1991. The hydraulic architecture of trees and other woody plants. New Phytologist 119:345-360.

Willson, C. J., P. S. Manos, and R. B. Jackson. 2008. Hydraulic traits are influenced by phylogenetic history in the droughtresistant, invasive genus Juniperus (Cupressaceae). American Journal of Botany 95:299-314.

Wright, I. J., et al. 2004. The worldwide leaf economics spectrum. Nature 428:821-827.

Wright, I. J., et al. 2010. Functional traits and the growthmortality trade-off in tropical trees. Ecology 91:3664-3674.

Zhang, J.-L., and K.-F. Cao. 2009. Stem hydraulics mediates leaf water status, carbon gain, nutrient use efficiencies and plant growth rates across dipterocarp species. Functional Ecology 23:658-667.

Zimmermann, M. H., and A. A. Jeje. 1981. Vessel-length distribution of some American woody plants. Canadian Journal of Botany 59:1882-1892.

Zotz, G., G. Harris, M. Koeniger, and K. Winter. 1995. Flora (Jena). 190:265-272.

\section{APPENDIX A}

A figure showing correlations between stem hydraulic conductivity and wood density in Ficus species (Ecological Archives E092184-A1).

\section{APPENDIX B}

A table showing results of phylogenetic signal tests for ecophysiological traits in Ficus species (Ecological Archives E092-184-A2). 